\title{
Diplomasi Publik Korea Selatan di Indonesia Melalui King Sejong Institute Center Indonesia
}

\author{
Naomi Karina Hutagalung ${ }^{1}$, Junita Budi Rachman², Akim $^{3}$ \\ ${ }^{1}$ Fakultas Ilmu Sosial dan Ilmu Politik, Universitas Padjajaran, Indonesia, naomi.hutagalung@hotmail.com \\ ${ }^{2}$ Fakultas Ilmu Sosial dan Ilmu Politik, Universitas Padjajaran, Indonesia, junita@unpad.ac.id \\ ${ }^{3}$ Fakultas Ilmu Sosial dan Ilmu Politik, Universitas Padjajaran, Indonesia, akim@unpad.ac.id
}

\begin{abstract}
ABSTRAK
Penelitian ini mengeksplorasi dan mengidentifikasi diplomasi publik Korea Selatan melalui King Sejong Institute Center Indonesia (KSIC). KSIC adalah institusi yang bergerak dibidang pendidikan bahasa dan budaya. Kehadirannya di Indonesia sebagai respon atas minat publik Indonesia yang gemar akan budaya Korea Selatan, khususnya budaya populer (Hallyu) yang mendorong keingintahuan mereka untuk lebih mengenal Korea Selatan. Dengan menggunakan metode penelitian kualitatif dan eksploratif dalam mengidentifikasi data pelaksanaan diplomasi publik di lapangan dengan menggunakan kerangka konseptual dimensi strategis diplomasi publik, untuk mengidentifikasi keberadaan elemen-elemennya, yaitu: listening, advocacy, cultural diplomacy, exchange diplomacy dan international broadcasting. Validasi penelitian ini dengan metoda triangulasi: studi literatur dan wawancara terhadap narasumber signifikan dan khalayak peserta. Hasil penelitian menunjukkan bahwa KSIC Indonesia telah melaksanakan diplomasi publik dan menerapkan beberapa elemenelemennya dalam kegiatan di setiap dimensi strategis. Walaupun demikian tidak semua elemen dapat dicakup dalam setiap dimensi pelaksanaannya. Melalui diplomasi publik yang dilaksanakan, KSIC Indonesia dalam waktu singkat telah dapat menarik perhatian masyarakat Indonesia terutama masyarakat Jakarta di mana tempat KSIC Indonesia berada. Hasil identifikasi terhadap hierarki penerimaan publik Indonesia yang merupakan hasil dari diplomasi publik KSIC Indonesia menandai bahwa KSIC Indonesia telah melaksanakan tugasnya sebagai perwakilan resmi Negara Korea Selatan.
\end{abstract}

Kata Kunci: Diplomasi Publik; Korea Selatan; King Sejong Institute Center Indonesia

\begin{abstract}
This research explores and identifies South Korean public diplomacy through King Sejong Institute Center Indonesia (KSIC). KSIC is an institution that works in language and cultural sector. Its presence in Indonesia is as a response for Indonesian public who enjoys South Korean culture, especially popular culture (Hallyu) that encourages their curiosity to know South Korean culture further. Using qualitative and exploratory research method in identifying public diplomacy implementation data on field and public diplomacy strategic dimension conceptual framework to identify the elements of existence; listening, advocacy, cultural diplomacy, exchange diplomacy and international broadcasting. This research is validated by applying triangulation method; literature study and interviews toward significant sources and general participants. The result shows that KSIC Indonesia is using public diplomacy and implementing several of its elements at events in every strategic dimension. However, not every element covers in every implementation dimension. Through applying public diplomacy, KSIC Indonesia has drawn Indonesian people attention especially Jakarta citizens where KSIC Indonesia is located in a short time. The Identification outcome towards Indonesian public acceptance hierarchy in which the result of KSIC Indonesia public diplomacy signifies that KSIC Indonesia has executed their task as an official representative of South Korea.
\end{abstract}

Keywords: Public Diplomacy; South Korea; King Sejong Institute Center Indonesia 


\section{Pengantar}

Negara pada dasarnya tidak dapat bertindak sendiri dalam memenuhi tujuan soft power nya di luar negeri. Untuk itu institusi nir-negara, khususnya yang lebih leluasa dalam mendekati target publik negara lain, kerap dibentuk. Melalui institusi nir-negara itu lah diplomasi publik dengan beberapa dimensi dan elemennya dilaksanakan untuk keperluan negara asal.

Korea Selatan merupakan salah satu negara yang termasuk ke dalam middle power country. Menurut Lee Sook Jong, pertumbuhan ekonomi Korea Selatan yang berkelanjutan sejak awal 1960-an telah mengubah negara miskin yang dulu bergantung pada bantuan menjadi kekuatan menengah ekonomi pada pertengahan 1990-an. ${ }^{1}$ Ini diakui secara internasional ketika Korea Selatan menjadi anggota organisasi untuk Operasi dan Pembangunan Ekonomi (OECD) pada tahun 1996. Dengan pemulihannya yang cepat dari krisis keuangan Asia 1997-98, GDP nominal Republik Korea menjadi yang terbesar kesebelas di dunia pada tahun $2002 .^{2}$

Saat terjadi krisis ekonomi dan finansial global pada tahun 1997, nilai perekonomian Korea Selatan melemah dan turun hingga $7 \%$. Sektor pariwisata yang jelas sekali menjadi pembangkit perekonomian negara ini sempat jatuh karena krisis yang melanda Asia. Untuk mengatasinya, pemerintah harus bekerja keras mencari cara agar nilai perekonomiannya membaik. Pada saat itu pemerintah mencoba untuk mengandalkan industri makanan sebagai jalan alternatif, namun pada kenyataannya hal tersebut tidak dapat membantu perekonomian membaik. Menanggapi situasi ini, Keith Dinnie, mengusulkan bahwa Korea Selatan

\footnotetext{
${ }^{1}$ Lee Sook Jong, South Korea as New Middle Power Seeking Complex Diplomacy. EAI Asia Security Initiative. 1-23. 2012.

${ }^{2}$ op.cit
}

memerlukan nation branding baru (Dinnie, 2009). ${ }^{3}$

Keberuntungan berpihak kepada Korea Selatan. Sejak pertengahan tahun 1990 telah berkembang fenomena baru yang kemudian membantu Korea Selatan yang tengah mencari alternatif bagi pemulihan perekonomiannya itu dan branding ulang negaranya (re-branding). Fenomena tersebut adalah kebangkitan popularitas Korean Wave. Namun, seperti yang disampaikan Seung-Ho Kwon and Joseph Kim, perjalanan Korea Selatan dalam mencapai keberhasilan dalam mempromosikan budayanya baik nasional maupun internasional tidak mudah. Berkat pemikiran ulang bahwa budaya dapat membawa dampak positif terhadap citra Korea Selatan, kemunculan fenomena Korean Wave tanpa hambatan dan pengekangan dapat mendatangkan efek positif bagi baik negara, bisnis dan juga masyarakat. ${ }^{4}$

Korean Wave merupakan budaya populer khas Korea Selatan dalam ragam bentuknya, seperti film, drama berseri, musik pop, Idol group band, yang disusul dengan fashion dan para-social relations. Secara masif popularitas budaya populer Korean Wave telah menyebar ke berbagai negara, mulai dari Cina, Hongkong, Taiwan dan Singapura, lalu menyebar ke negara-negara Asia Tenggara seperti Vietnam, Thailand, Malaysia dan Indonesia, diikuti oleh Jepang, Mongolia dan bahkan negara di luar Asia. ${ }^{5}$ Popularitas Korean Wave yang semakin meluas ini disertai dengan meluasnya minat publik mancanegara untuk mengonsumsi apapun yang berasal dari Korea Selatan. Pada tahun 2005 terdapat data yang menunjukkan bahwa Korean Wave

\footnotetext{
${ }^{3}$ Keith Dinnie. Repositioning the Korea Brand to a Global Audience: Challenges, Pitfalls and Current Strategy. Korea Economics Institute Academic Paper Series. 1-5. 2009

${ }^{4}$ Seung-Ho Kwon and Joseph Kim, From censorship to active support: The Korean state and Korea's cultural industries. The Economic and Labour Relations Review. 517-529. 2013

${ }^{5}$ Yang, Jonghoe. The Korean Wave (Hallyu) in East Asia: A Comparison of Chinese, Japanese and Taiwanese Audiences Who Watch Korean TV Dramas. Development and Society. 20. 2012
} 
meningkatkan GDP Republik Korea sebanyak $0,2 \%$. Korean Wave menyokong $\$ 1,87$ miliar atau 2,14 triliun Won pada sektor ekspor dan pariwisata pada tahun 2004. Korean Wave mampu menyumbang $\$ 918$ miliar dalam bidang penjualan produk lokal. ${ }^{6}$ Fenomena Korean Wave seperti ini kemudian tak dilewatkan oleh Pemerintah Korea Selatan untuk kemudian diberdayakan kemanfaatannya bagi negara.

Jang Gun-joo, Paik Won $\mathrm{K}$ melihat bahwa Korean Wave memengaruhi posisi politik dan diplomasi. Pengaruh ini dilihat sebagai dampak yang positif dan memiliki potensi untuk mempromosikan diplomasi budaya Korea Selatan sebagai bagian dari pendekatan soft power. Hal ini telah terlihat manfaatnya dalam hubungan Taiwan dan Republik Korea yang sempat menjadi dingin pasca putusnya hubungan diplomatik kedua negara pada tahun 1992. Korean Wave memberikan gambaran bahwa Korea Selatan memiliki citra yang positif dan memberi kesempatan bagi kedua negara untuk melakukan rekonsiliasi. Selain memperbaiki hubungan dengan negara lain, Korean Wave juga dapat dilihat sebagai pembuka jalan bagi kerja sama bisnis antar negara. ${ }^{7}$ Pentingnya terdapat kesamaan budaya di antara negaranegara sekawasan dikemukakan oleh Cho Young-han dalam penelitiannya. Dengan kesamaan budaya ini keberhasilan secara kawasan bisa dicapai karena adanya kesamaan budaya atau mental dari negara-negara yang berasal dari satu kawasan. Mengenai hal ini Cho melihat bahwa Korean Wave dapat menjadi contoh bagi negara-negara lain untuk menggunakan budaya untuk mempererat hubungan satu dengan lain. Dibutuhkan kolaborasi dari sejarah dan kerja sama horizontal antar negara. Menurut Cho, budaya populer dapat menjadi salah satu kekuatan dari

\footnotetext{
${ }^{6}$ Visit Korea. english.visitkorea.or.kr. diakses 15 Februari 2018

${ }^{7}$ Jang Gun-joo, Paik Won K. Korean Wave as Tool for Korea's New Cultural Diplomacy. Advance in Apllied Sociology. 196-202. 2012
}

negara-negara di Asia Timur. ${ }^{8}$ Selain itu, Taekyoon Kim, Huck-Ju Kwon, Jooha Lee, Ilcheong Yi melihat sangat penting bagi pelaksanaan soft power Korea Selatan untuk bekerja sama dengan berbagai aktor nir-negara sebagai perpanjangan tangan pemerintah untuk meningkatkan pertumbuhan ekonomi. ${ }^{9}$

Pada tahun 2006, Pemerintah menetapkan Korean Wave sebagai instrumen diplomasi publik dan tertuang dalam Diplomatic White Paper Republik Korea part 3, Advance Diplomacy in The International Arena, Chapter 5, Enhancement of Cultural and Public Relations for the Promotion of Dynamic Korea. Korean Wave tertuang dalam pelaksanaan diplomasi publik yang diputuskan oleh pemerintah Korea Selatan ini tentunya membutuhkan agen sebagai perpanjangan tangan pemerintah untuk mengaplikasikannya. Ministry of Culture, Sport and Tourism (MCST) ditunjuk langsung sebagai agen pemerintah Korea Selatan dan bertanggungjawab dalam segala kegiatan budaya, olahraga dan pariwisata. ${ }^{10}$ Selanjutnya institusi yang berfokus pada promosi bidang budaya dibentuk, yaitu Korean Cultural Center (KCC) yang dikelola oleh kedutaan besar Korea Selatan. KCC sendiri telah tersebar di 28 negara di dunia termasuk Indonesia. ${ }^{11}$ Melihat keberhasilan dari KCC dalam mempromosikan budaya populer, Pemerintah Korea memutuskan untuk membentuk suatu institusi lain yang berfokus kepada penyebaran bahasa Korea. Hal ini disebabkan tingginya minat masyarakat internasional untuk mengetahui lebih dalam

\footnotetext{
${ }^{8}$ Cho Young-han. Desperately Seeking East Asia Amidst The Popularity of South Korean Pop Culture in Asia. Cultural Studies. 383-398. 2011

${ }^{9}$ Kim Taekyoon, Kwon Huck-Ju, Lee Jooha, Yi Ilcheong. Mixed Governance and Welfare in South Korea. Journal of Democracy. 120-134. 2011 ${ }^{10}$ Ministry of Foreign Affairs Republic of Korea. Diplomatic White Paper. mofa.go.kr. Diakses 25 Februari 2018

${ }^{11}$ Ministry Culture, Sport and Tourism. Korean Cultural Center. http://www.kocis.go.kr/eng/openInformation.do. Diakses 26 Maret 2019
} 
mengenai budaya dan gaya hidup masyarakat Korea yang membuat mereka ingin mengetahui bahkan mempelajari bahasa Korea. Selanjutnya untuk tujuan tersebut MCST membentuk The King Sejong Institute Foundation (KSIF) pada tahun 2012 setelah melalui proses perencanaan sejak tahun 2008.

Namun, selain sebagai institusi bahasa yang bertujuan untuk menyebarkan bahasa Korea di seluruh dunia, dalam praktiknya KSIF juga melaksanakan diplomasi publik Korea Selatan di negara institusi itu berada. Dalam hal ini KSIF mempromosikan budaya Korea yang lebih luas. KSIF itu sendiri memiliki visi dan misi yang telah disetujui sebagai dasar dalam menjalankan lembaga ini. Visinya adalah menjadi institusi utama di Korea Selatan yang berkomunikasi dengan dunia melalui bahasa dan budaya. Sementara misinya adalah mendistribusikan bahasa dan budaya Korea Selatan sebagai bahasa asing atau bahkan menjadi bahasa kedua. Selain itu juga mendukung penguatan bisnis-bisnis mandiri dan menjadi pionir bagi kebijakankebijakan pemerintah Korea Selatan. Melalui bahasa dan budaya diyakini dapat melancarkan komunikasi dan kesepemahaman yang menguntungkan bagi pihak-pihak yang terlibat, dalam hal ini bagi Korea Selatan.

Dalam situs jaringan KSIF, sampai pada Juni 2019, tercatat sebanyak 180 King Sejong Institute (KSI) yang tersebar di 60 negara di dunia, empat diantaranya terdapat di Indonesia. Satu institusi berada di Surabaya dan tiga institusi lainnya berada di Jakarta. Empat institusi yang berada di Indonesia terdiri dari jenis KSI yang berbeda. KSI Surabaya merupakan tipe connective yaitu hasil kerja sama Universitas Petra (Indonesia) dengan Universitas Dongseo (Korea Selatan). KSI Surabaya berdiri sejak tanggal 10 Agustus 2015. KSI di Jakarta sendiri terdiri dari dua tipe KSI yang berbeda. Dua KSI di Jakarta merupakan tipe connective, satu KSI tergabung dalam Korean Cultural Center (KCC) yang dikelola oleh Kedutaan Korea Selatan di Indonesia dan satu lagi merupakan hasil kerja sama Universitas Nasional (Indonesia) dengan Universitas Katolik Daegu (Korea Selatan). Dalam pengelolaannya, KSI dengan tipe connective dikelola sesuai dengan peraturanperaturan yang dimiliki oleh institusi pengelola. Biasanya KSI ini hanya mengadaptasi kurikulum yang dimiliki KSIF namun dalam aspek lain dikelola sesuai kebijakan instansi pengelola masing-masing. Satu KSI merupakan KSI dengan tipe independen yaitu KSI Center (KSIC) yang dibentuk berdasarkan keputusan langsung dari kantor pusat yaitu KSIF dan merupakan perwakilan KSIF di Indonesia. ${ }^{12}$

\section{Pentingnya KSIC beroperasi di} Indonesia semakin meningkat sejak Korean Wave mulai merambah Indonesia pada tahun 2000-an. Menurut Korea Tourism Organization (KTO) data menunjukkan bahwa pada tahun 2008 lebih dari 80.000 warga Indonesia mengunjungi Korea Selatan. Pada tahun 2012 jumlahnya meningkat menjadi 150.000 dan mendekati 190.000 pada tahun 2013. Jumlah ini terus meningkat hingga pada tahun 2017 lebih dari 230.000 warga Indonesia menjadi turis di Korea Selatan. ${ }^{13}$ Dari data ini dapat dilihat bahwa antusiasme warga Indonesia semakin meningkat setiap tahunnya. KTO telah meluncurkan situs jaringan baru yang disebut dengan \#AkudanKorea yang menargetkan warga Indonesia dengan konsep Free and Independent Travellers (FIT). KTO memberikan penjelasan bahwa Korea Selatan dengan kemudahan trasportasi umum dan keamanan yang tinggi merupakan tujuan wisata yang tepat bagi turis yang bepergian sendiri. Untuk menjaga kesinambungan dan bahkan meningkatkan minat publik Indonsia terhadap Korea Selatan, KSIC sebagai perpanjangan tangan pemerintah Korea Selatan,

\footnotetext{
${ }^{12}$ KSIs Worldwide. King Sejong Institute Foundation.

https://www.ksif.or.kr/ste/ksf/hkd/lochkd.do?menu No=31101100. Diakses 1 Juli 2019

${ }^{13}$ Joy Muchtar. Hallyu: Surfin' the Korean Wave in Indonesia. https://jakartaglobe.id/culture/riding-thewave-of-south-korean-pop-culture-in-indonesia. Diakses 20 Mei 2018
} 
meluncurkan strategi-strategi diplomasi publik tersendiri baik jangka panjang, menengah dan pendek atau sehari-hari, berserta elemenelemen substansi yang menarik. Penelitan ini akan mengeksplorasi, mengidentifikasi dan menjelaskan bagaimana strategi-strategi dan elemen-elemen diplomasi publik dilaksanakan oleh KSIC Indonesia, khususnya yang berpusat di Jakarta.

\section{Kerangka Teori}

Setiap negara memiliki kepentingan nasional yang harus dicapai. Untuk mencapai kepentingan nasionalnya itu negara membutuhkan power. Dalam hal ini power itu sendiri dibedakan menjadi dua: hard power yang pada umumnya meliputi kekuatan militer; serta soft power yang pada umumnya meliputi kekuatan diplomasi. Pada awalnya definisi soft power adalah kemampuan untuk memengaruhi pihak atau bangsa lain agar mau menuruti kemauannya melalui serangkaian kegiatan yang tidak melibatkan kekerasan melainkan kemenarikan-kemenarikan. ${ }^{14}$

Nye menuliskan setidaknya terdapat tiga sumber soft power, yang pertama budayanya, kedua nilai politiknya, dan yang ketiga adalah kebijakan luar negerinya (2008: 96). Pemberdayaan sumber-sumber soft power dalam mengejar kepentingan nasional negara membutuhkan aktor-aktor bukan negara (nonstate actors) seperti agen-agen swasta, institusi keagamaan dan pendidikan, serta perusahaan transnasional yang bergerak dalam bisnis perdagangan, komunikasi dan informasi, seni, dan budaya yang lebih leluasa berhubungan langsung dengan masyarakat. Nye menilai bahwa tidaklah mudah untuk melaksanakan soft power, karena banyak sumber-sumber yang penting dalam soft power merupakan sumber yang tidak dapat dikendalikan pemerintah dan efek dari soft power itu sendiri sangat bergantung terhadap penerimaan dari masyarakat. Terlebih lagi dalam melaksanakan

\footnotetext{
${ }^{14}$ Joseph S. Nye, Jr. Public Diplomacy and Soft Power. Sage Publications, Inc. 94. 2008
}

soft power dibutuhkan waktu yang cukup lama dalam membangun ketertarikan dan rasa percaya antar sebuah negara. ${ }^{15}$

Diplomasi publik merupakan salah satu instrumen soft-power. Definisi diplomasi publik dikemukakan oleh $\mathrm{H}$. Tuch, yaitu: " $A$ Government's process of communicating with foreign publics in an attempt to bring about understanding for its nation's ideas and ideals, its institutions and culture, as well as its national goals and current policies". ${ }^{16}$ Menurut Tuch, diplomasi publik merupakan suatu proses dari pemerintahan dalam bentuk komunikasi dengan publik luar negeri dan mengusahakan adanya pengertian mengenai ide dan idealnya negara, institusi-institusi dan kebudayaannya, begitu pula dengan tujuan nasional dan kebijakan negara tersebut.

Pelaksanaan diplomasi publik oleh Leonard dibagi ke dalam tiga dimensi. ${ }^{17}$ Dimensi pertama adalah diplomasi publik berupa komunikasi sehari-hari (day to day) berkenaan dengan penjelasan konteks keputusan kebijakan luar negeri dan domestik negaranya. Tujuannya untuk menggiring opini publik mengenai isu-isu yang terjadi di negaranya sesuai denga keinginan pemerintah negara tersebut. Dimensi kedua adalah diplomasi publik berupa komunikasi strategis (Strategic Communication), yaitu aktivitas melalui berbagai acara yang kerap dikemas program-program yang layaknya seperti kampanye politik dengan tujuan untuk mempromosikan negara atau nilai-nilai positif negaranya secara keseluruhan. Dimensi ketiga, adalah diplomasi publik pembangunan relasi antar aktor (Relationship Building) melalui pemberian beasiswa, pertukaran pelajar, kegiatan pelatihan (training), seminar atau konferensi, dan akses-akses saluran media lainnya. Negara mengelola lingkungan

\footnotetext{
15 Joseph. S. Nye, Jr. Soft Power: The Means to Success in World Politics. Public Affairs. 2004 16 Tuch, H. N. Communicating with the world: U.S public diplomacy overseas. St. Martin's Press. 1990 ${ }^{17}$ Mark Leonard. Public Diplomacy. The Foreign Policy Centre. 12-21. 2002
} 
internasionalnya dengan berbagai cara, salah satunya melalui diplomasi publik. Diplomasi publik memiliki beberapa elemen fungsi penting dalam pelaksanaannya. Diantaranya adalah Listening, Advocacy, Cultural Diplomacy, Exchange Diplomacy dan International Broadcasting. 18 Listening merupakan upaya mengumpulkan data terkait dengan publik dan pendapat yang berasal dari luar negeri dan menggunakan data tersebut sebagai panduan untuk melakukan perbaikan terhadap sebuah kebijakan atau untuk melakukan pendekatan diplomasi publik yang lebih luas. Pada dasarnya listening menjadi dasar bagi elemen-elemen lain dalam diplomasi publik seperti advocacy, cultural diplomacy, exchange diplomacy dan international broadcasting sesuai dengan khalayak yang dimiliki oleh masing-masing elemen. Elemen advocacy merupakan upaya komunikasi internasional secara aktif untuk mempromosikan kebijakan, ide maupun kepentingan aktor kepada masyarakat internasional. Elemen Cultural Diplomacy merupakan upaya pengenalan budaya yang dimiliki melewati batas negara dan memfasilitasi transmisi budaya keseluruh dunia. Secara historis, upaya ini juga dikenal sebagai kebijakan yang memfasilitasi ekspor kebudayaan yang dimiliki dan dapat digunakan dalam jangka panjang oleh agen kebudayaan berupa pembukaan pusat-pusat kebudayaan dan perpustakaan. Elemen exchange diplomacy merupakan upaya memfasilitasi warga negaranya untuk tinggal di negara lain dan menerima warga negara lain untuk tinggal di negaranya dalam jangka waktu tertentu dengan tujuan baik studi atau akulturasi maupun keduanya. Pertukaran pelajar maupun warga negara lainnya ini didasarkan pada konsep saling menguntungkan bagi masing-masing pihak yang mendapatkan pengalaman dan pembelajaran yang dialami di negara tujuan. Elemen international broadcasting merupakan upaya berhubungan dengan masyarakat

\footnotetext{
${ }^{18}$ Cull, J. N. Public Diplomacy: Lessons from the
} past. Figueroa Press. 18-22. 2009 internasional melalui penggunaan teknologi seperti radio, televisi dan internet.

Ketiga dimensi dan elemen-elemen fungsi diplomasi publik diatas merupakan strategi dalam diplomasi publik untuk memengaruhi target reception. ${ }^{19}$ Pada dasarnya tujuan diplomasi publik adalah untuk mempengaruhi masyarakat negara lain untuk memandang negaranya sesuai yang diinginkan. Menurut Leonard, terdapat empat hierarki tingkatan pengaruh yang menjadi tujuan dilakukannya diplomasi publik oleh suatu negara yaitu familiarity, appreciation, engaging people dan influencing.

Familiarity merupakan pengaruh dengan hierarki paling dasar. Programprogram yang dirancang diharapkan memberikan pengaruh terhadap masyarakat internasional yang mulai memikirkan tentang negara tersebut, memperbaharui citra negaranya dan dapat mengubah pendapat yang awalnya tidak berpihak kepada negara tersebut menjadi berpihak kepada mereka. Hierarki pengaruh berikutnya adalah appreciation. Untuk mencapai pengaruh ini, tugas aktor yang melaksanakan diplomasi publik adalah menciptakan persepsi yang positif terhadap negaranya sehingga mengajak masyarakat publik internasional untuk melihat isu global yang ada dari sudut pandang yang sama. Engaging people merupakan sebuah pengaruh yang dapat dilihat hasilnya dari kerja samakerjasama yang dilakukan antar negara. Kerja sama yang dilakukan baik dalam bidang pendidikan hingga sains, menstimulasi masyarakat internasional untuk melihat negaranya sebagai sebuah negara yang menarik untuk dikunjungi (wisata), belajar, pembelajaran jarak jauh, membuat masyarakat internasional membeli produk negaranya, membuat mereka mengerti dan mengikuti nilai-nilai yang dimiliki oleh negaranya. Seluruh pengaruh yang disebutkan diatas merupakan bukti bahwa pada hierarki ini sudah terjalin hubungan antara negara dan

\footnotetext{
${ }^{19}$ Mark Leonard. Public Diplomacy. The Foreign
} Policy Centre. 8-9. 2002 
masyarakat internasional yang semakin erat. Hierarki terakhir adalah influencing. Influencing dapat dilihat dari banyaknya perusahaan-perusahan untuk berinvestasi, opini publik yang mendukung serta para politisi yang berpaling menjadi menyukai negara tersebut. Sejak dominasi pendekatan state centric telah bergeser kepada pendekatan non-state centric, pelaksanaan diplomasi publik oleh para palaku bukan negara dapat menjadi agen baik resmi maupun tidak resmi dalam melaksanakan dan memperjuangkan kepentingan negaranya di luar negeri.

\section{Metode}

Penelitian ini menggunakan metode kualitatif deskriptif untuk mengeksplorasi dan mengidentifikasi bagaimana KSIC di Indonesia melaksanakan elemen-elemen diplomasi publik Korea Selatan. Data diperoleh di lapangan dan wawancara sebagai data primer dan data kepustakaan dari dokumen, jurnal akademik, artikel berita, situs jaringan dan media sosial sebagai data sekunder. Semua data kemudian diseleksi dan diklasifikasikan ke dalam tiga dimensi diplomasi publik. Selanjutnya untuk validasi triangulasi dilaksanakan dengan menyertakan pula pendapat ahli, pengamat dan peserta program KSIC (target utama diplomasi publik).

\section{Pembahasan}

KSIC merupakan institusi independen yang langsung berada di bawah pengawasan King Sejong Institute Foundation (KSIF) dan bergerak dalam bidang bahasa dan budaya Korea Selatan. Sampai pada tahun 2019 terdapat tiga KSIC di seluruh dunia, yaitu Amerika Serikat, Vietnam dan Indonesia. Namun insitutusi yang sudah aktif beroperasi adalah KSIC Indonesia dan KSIC Amerika Serikat sedangkan KSIC Vietnam sedang dalam tahap perizinan.

KSIC Indonesia berdiri pada akhir 2016 dan mulai beroperasi pada September 2017. Pada awal beroperasi, KSIC Indonesia memiliki 75 orang yang terdaftar sebagai murid. Dalam kurun waktu kurang lebih satu tahun, jumlah murid mengalami kenaikan yang sangat signifikan menjadi kurang lebih 400 orang. Menurut narasumber, saat ini KSIF melihat potensi yang dimiliki negara-negara Asia Tenggara yang memiliki ketertarikan dengan budaya Korea Selatan.

Peningkatan jumlah warga di Jakarta yang tertarik dan menjadi murid KSIC Indonesia telah membuat KSIC Indonesia melihat potensi yang besar yang masih dapat digali lebih luas lagi. Untuk itu, KSIC Indonesia melakukan berbagai kegiatan yang masuk dalam kategori diplomasi publik. Diplomasi publik KSIC Indonesia yang ditujukan kepada publik Indonesia dilaksanakan secara tertata dalam dimensi waktu yang memuat elemen-elemen diplomasi, yaitu listening, advokasi, diplomasi budaya, diplomasi pertukaran dan siaran internasional

Berikut ini merupakan hasil identifikasi kegiatan elemen-elemen diplomasi publik KSIC yang dilaksanakan terhadap publik Indonesia sebagai sasaran di dalam setiap dimensi.

\section{Pelaksanaan dan Elemen-Elemen Diplomasi Publik Dalam Komunikasi Sehari-hari}

Dimensi pertama diplomasi publik KSIC Indonesia berupa komunikasi sehari-hari (day to day communication) berkenaan dengan penjelasan konteks keputusan kebijakan luar negeri dan domestik negara Korea Selatan. Tujuannya adalah untuk menggiring opini dan dan meningkatkan awareness publik Indonesia mengenai isu-isu yang terjadi di negara Korea Selatan sesuai dengan keinginan pemerintah negara itu. Dalam pelaksanaannya, diplomasi publik dalam komunikasi sehari-hari 
Gambar 1. Salah satu survey KSIC melalui IG
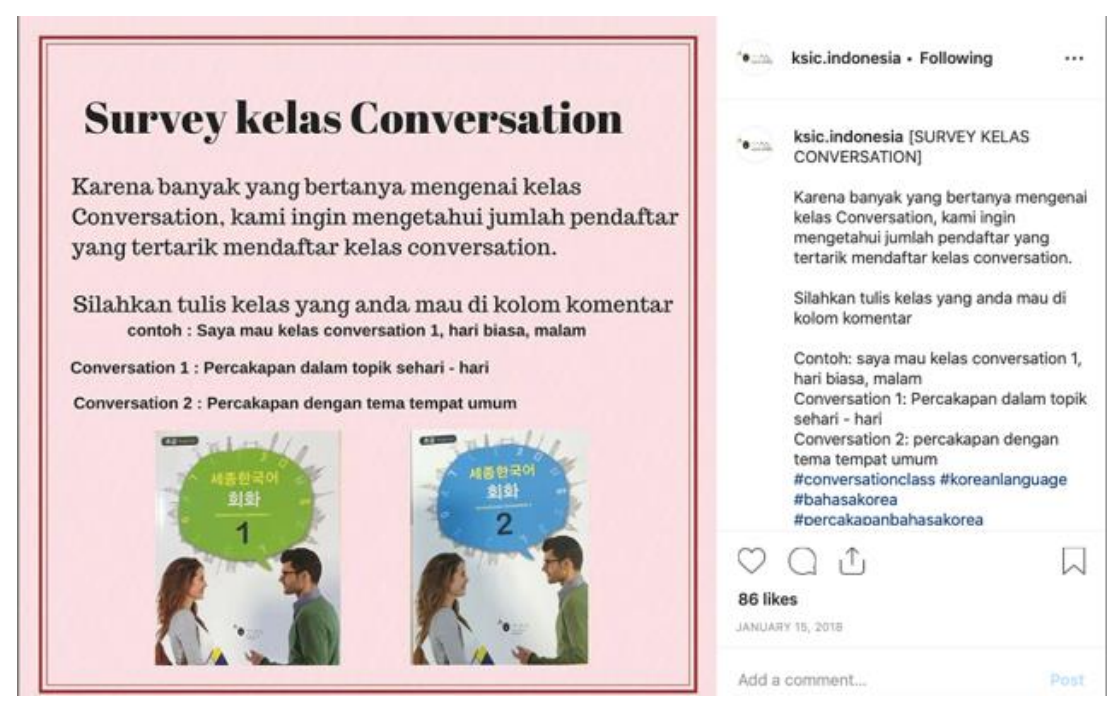

dijalankan KSIC Indonesia melalui meja bantuan (help desk) khusus yang berhubungan dengan khalayak. Help desk ini tidak sekedar memberikan informasi dan laporan mengenai kegiatan program-program KSIC Indonesia dalam bidang budaya, pendidikan bahasa, dan olahraga, melainkan utamanya adalah memberikan informasi mengenai perkembangan terbaru Korea Selatan diberbagai bidang dan tanggal-tanggal penting bagi Korea Selatan, serta mengenai politik di Korea Selatan, khususnya yang berdampak positif bagi citra negaranya.

Selain itu, KSIC Indonesia juga menggunakan salah satu platform media sosial bagi komunikasi sehari-hari dengan publik Indonesia, yaitu Instagram (IG) dan Facebook (Fb). Akun IG dengan nama: @ksic.indonesia dapat dijumpai dengan mengunjungi tautan: http://instagram.com/ksic.indonesia?igshid=16 gs2teicbh7u sedangkan akun FB dengan nama King Sejong Institute Center Indonesia dapat dijumpai dengan mengunjungi tautan: https://www.facebook.com/ksic.indonesia/.

Dalam akun IG yang dikelola KSIC Indonesia tersebut, pada Juli 2019 terlihat jumlah postingan sebanyak 488 foto dan video dengan jumah pengikut (follower) sebanyak 7.324 orang. Semua foto dan video tersebut memperlihatkan aktivitas ragam kegiatan para peserta KSIC Indonesia, dalam hal ini para murid akademi bahasa dan kebudayaan Korea, terutama yang berada di Jakarta. Dalam setiap postingan foto dan video terdapat komentarkomentar dari para peserta yang terlibat maupun dari para follower atau pengunjung. Sementara dalam $\mathrm{Fb}$ akun King Sejong Institute Center Indonesia yang menggunakan bentuk laman fans pada Juli 2019 terlihat yang memberi tanda suka (like) sebanyak 10.054 orang dan yang menjadi pengikut sebanyak 10.144. Isi dari akun ini tidak jauh berbeda dengan apa yang terdapat di akun IG KSIC Indonesia itu.

Dalam pelaksanaan diplomasi publik pada dimensi komunikasi sehari-hari melalui help desk dan media sosial tersebut, pada dasarnya KSIC Indonesia menerapkan elemenelemen pentingnya. Elemen listening termasuk dalam melihat respon masyarakat melalui komentar-komentar yang diberikan para followers pada akun Instagram dan Fb KSIC itu. KSIC juga melakukan survei singkat, misalnya adalah untuk mengetahui seberapa antusias masyarakat Jakarta mengenai rencana kelas baru yang akan dibuka. 
Elemen advokasi walau dalam bentuk yang sederhana, misalnya dalam memberikan informasi-informasi terkait kebijakankebijakan Korea Selatan yang berhubungan dengan visa menikah, apa itu visa menikah dan bagaimana ketentuan-ketentuan dalam pembuatan visa menikah tersebut. Selain itu elemen diplomasi budaya Korea Selatan juga difungsikan dengan memberikan informasi dan promosi budayanya, terutama yang diminati oleh masyarakat Indonesia, yaitu mengenai budaya tradisional dan Korean Wave serta olahraga bela diri Taekwondo.

Melalui dimensi komunikasi seharihari beserta elemen diplomasi publik, KSIC Indonesia berusaha selain untuk mengelola awareness publik Indonesia terhadap apa yang sedang terjadi di Korea Selatan dan agar semakin banyak publik Indonesia yang tertarik dan menyukai negara Korea Selatan serta segala yang berasal dan berkaitan dengan negara itu.

\section{Pelaksanaan dan Elemen-Elemen Diplomasi Publik Dalam Komunikasi Strategis}

Dimensi kedua diplomasi publik KSIC Indonesia di Indonesia berupa komunikasi strategis (Strategic Communication), yaitu aktivitas melalui berbagai program acara yang dikemas layaknya sebuah kampanye politik. Tujuannya adalah untuk mempromosikan nilai-nilai positif negara Korea Sealatan secara keseluruhan. Caranya adalah dengan melibatkan langsung publik Indonesia dalam upaya mempromosikan budaya Korea Selatan. Pada umur KSIC Indonesia yang tergolong masih sangat muda yaitu hampir dua tahun, namun telah memiliki program-program acara yang dilaksanakan setiap bulannya. Berikut ini merupakan komunikasi strategis dan elemenelemen diplomasi publik KSIC Indonesia melalui ragam program kerja yang melibatkan publik Indonesia.

\section{Korean Culture Day (KCD)}

KCD merupakan kegiatan rutin bulanan KSIC yang bertujuan untuk memberikan pemahaman lebih mendalam mengenai berbagai budaya baik tradisional maupun populer yang dimiliki oleh Korea Selatan. Setiap bulannya, KCD memiliki tema yang berbeda dan disajikan dengan berbagai kegiatan menarik yang melibatkan para murid KSIC. Dalam setiap kegiatan KCD, para pengajar selalu memberikan materi pengajaran kepada para murid atau peserta KCD sesuai dengan tema yang dipilih pada bulan tersebut. Selain materi pengajaran, KSIC juga memberikan kesempatan kepada para murid untuk berkreasi dalam membuat benda-benda tradisional Korea Selatan.

Pada acara KCD April 2019 yang dihadiri peneliti, terlihat KSIC memberikan penjelasan mengenai etiket makan masyarakat Korea Selatan. Mulai dari yang bersifat tata krama, cara memegang alat makan yaitu berupa sendok dan sumpit hingga membuat piring tradisional yang terbuat dari kertas. KSIC kemudian mengundang para peserta untuk aktif terlibat dalam pembuatan piring tradisional itu dan dalam tanya jawab. Dengan suasana yang ramah membuat para peserta sangat menikmati rangkaian acara yang disusun oleh KSIC. Para staf KSIC sangat aktif dalam membantu para peserta apabila mengalami kesulitan. Selain itu KSIC juga menyiapkan makanan dan minuman ringan yang disediakan bagi peserta untuk dinikmati bersama selama acara berlangsung. Pada umumnya setiap KCD yang diselenggarakan oleh KSIC, para peserta mendapat souvenir yang berhubungan dengan tema KCD. Pada KCD April, KSIC Indonesia meberikan souvenir gratis berupa satu set alat makan yang terdiri dari sendok dan sumpit khas Korea Selatan.

Acara KCD lainnya adalah mengundang para murid, peserta atau pengikut KSIC Indonesia serta masyarakat umum untuk datang dan menikmati film-film Korea secara gratis di bioskop CGV. KSIC Indonesia 
memanfaatkan kepopuleran Korean Wave dalam bentuk film untuk menjaring lebih banyak lagi masyarakat yang terlibat. Setelah kegiatan selesai, KSIC Indonesia mengadakan kelas yang mencoba membedah budaya Korea sesuai dengan film yang ditayangkan.

Dalam kegiatan KCD terlihat elemenelemen diplomasi publik yang dilaksanakan. Elemen pertama merupakan elemen listening. Para peserta KCD diberikan waktu untuk bertanya dan berdiskusi baik dengan sesama peserta maupun dengan narasumber yang ada. Para staf juga aktif berkeliling dan mengunjungi setiap meja untuk membantu para peserta dan mendengarkan kesan dan pesan para peserta yang hadir dalam KCD tersebut. Elemen lainnya adalah diplomasi budaya. KSIC Indonesia selalu mengusung tema budaya dalam setiap kegiatan KCD. Namun menurut narasumber, KSIC Indonesia lebih fokus mengangkat tema budaya tradisional Korea. Sebagai contoh adalah Taekugi (bendera Korea Selatan), Hangeul \& Kaligrafi, etika makan, Hanbok, pernikahan tradisional dan Samulnori (musik tradisional Korea). KSIC Indonesia tidak sepenuhnya menghilangkan budaya popular dalam tema KCD yang kadang kala juga dimunculkan, diantaranya dalam acara tari dan nyanyi bersama dan menonton film-film populer Korea.

Setelah selesai melakukan program, KSIC Indonesia mengunggah dokumentasidokumentasi kegiatan ke akun Instagram dan Facebook yang dimiliki agar masyarakat Indonesia dapat mengetahui informasi mengenai kegiatan-kegiatan yang dilakukan KSIC Indonesia. Dalam hal ini KSIC Indonesia melaksanakan elemen siaran internasional.

\section{Corporate Social Responsibility (CSR)}

Walaupun usia KSIC Indonesia masih muda, namun KSIC telah melakukan Corporate Social Responsibility (CSR) pada bulan Desember 2018 dan akan menjadi program tahunan selanjutnya. Pada CSR pertama yang diberi nama Sharing for caring,
KSIC mengunjungi Panti Asuhan Yayasan Murni Jaya. Beberapa kegiatan yang dilakukan adalah membersihkan dan mengecat pagar bagian luar panti, serta memasak kuliner tradisional Korea Selatan.

KSIF mewajibkan seluruh KSIC untuk menjalankan kegiatan CSR setiap tahunnya. Kegiatan ini merupakan bentuk nyata dari kepedulian pemerintah Republik Korea yang dalam hal ini diwakilkan oleh KSIF terhadap masyarakat di tempat KSIC berada. Dengan adanya CSR ini, KSIC berharap seluruh masyarakat Indonesia dari semua kalangan dapat merasakan kehadiran dan eksistensi dari Korea Selatan.

Dalam kegiatan CSR, KSIC Indonesia berupaya menjadi perpanjangan tangan pemerintah Korea Selatan dalam menyalurkan bantuan-bantuan kepada masyarakat Indonesia yang kurang beruntung. Kegiatan ini sendiri mengandung elemen listening. Para staf akan berdiskusi dengan para anak di panti asuhan dan mendengarkan pendapat-pendapat mereka mengenai budaya Korea. Selain berdiskusi mengenai budaya Korea, para staf menggunakan kesan-kesan dan pesan mengenai CSR ini untuk membuat program CSR berikutnya menjadi lebih baik.

Dalam kegiatannya membantu membersihkan panti, KSIC Indonesia juga secara langsung melakukan elemen diplomasi budaya. KSIC Indonesia menyediakan makanan-makanan tradisional untuk mengenalkan kepada semua anak makanan tradisonal Korea. Tidak hanya sekedar menyediakan, KSIC Indonesia melakukan kegiatan memasak yang dapat disaksikan oleh semua anak sehingga mereka mengetahui bahan-bahan tradisional Korea dan proses masak memasaknya.

\section{Kelas visa menikah}

KSIC Indonesia merupakan institusi resmi negara Korea Selatan yang dapat memberikan informasi-informasi mengenai kebijakan-kebijakan atau peraturan-peraturan yang berhubungan dengan kebudayaan atau beberapa kebijakan lain yang salah satunya 
adalah mengenai visa menikah atau visa F-6. Salah satu syarat yang harus dipenuhi dalam pembuatan visa F-6 adalah sertifikat bahasa yang dikeluarkan oleh KSI. Berkenaan dengan dengan hal ini, KSIC melaksanakan elemen listening, elemen advokasi dan elemen diplomasi budaya Korea Selatan. Di antaranya, KSIC Indonesia menyediakan layanan bagi masyarakat Indonesia yang ingin bertanya mengenai prosedur-prosedur yang dibutuhkan oleh para pelamar visa menikah. Lebih lanjut, KSIC Indonesia juga menyediakan kelas bahasa, termasuk budaya di dalamnya, bagi pasangan yang ingin mengajukan visa F-6 untuk mendapatkan sertifikat bahasa yang diakui oleh pemerintah Korea sebagai salah satu syarat pengajuan visa nikah. Kelas ini berlangsung selama satu tahun.

\section{Pelaksanaan dan Elemen-Elemen Diplomasi Publik Dalam Dimensi Relationship Building}

Dimensi ketiga adalah diplomasi publik KSIC Indonesia di Indonesia berupa pembangunan relasi (Relationship Building) dengan publik Indonesia melalui program tetap dan berkelanjutan. Tujuannya adalah untuk membangun relasi yang potensial dan prospektif dengan publik Indonesia yang bermanfaat bagi Korea Selatan. Caranya adalah dengan pemberian beasiswa, pertukaran pelajar, kegiatan pelatihan (training), seminar atau konferensi, dan akses-akses saluran media lainnya. Dalam pembangunan relasi ini terdapat pelaksanaan elemen-lemen diplomasi publik.

Berikut ini adalah pelaksanaan diplomasi publik beserta elemen-elemennya yang dilakukan oleh KSIC Indonesia dengan publik Indonesia yang memenuhi syarat dan yang memiliki ketertarikan terhadap apapun dari Korea Selatan.

\section{Kelas Bahasa Korea}

KSIC Indonesia memiliki kelas bahasa Korea yang diajar oleh pengajar native yang profesional dan telah mendapat pengarahan dari KSIF. KSIC Indonesia saat ini memiliki 20 kelas bahasa yang memiliki peserta sebanyak 20-25 orang setiap kelasnya. Tidak hanya kelas bahasa yang mempelajari teori namun KSIC juga membuka kelas conversation. Melalui kelas ini diharapkan para murid dapat lebih mudah menerapkan bahasa Korea dalam percakapan sehari-hari. Melalui pembelajaran bahasa ini pula, budaya dan gaya hidup Korea Selatan secara inheren mengikuti dan tertanam ke dalam setiap diri murid. Para murid kelas bahasa Korea ini pada dasarnya merupakan sasaran terdekat diplomasi publik KSIC Indonesia pada dimensi sehari-hari dan dimensi strategis, yang kemudian pada dimensi berikutnya diharapkan dapat terbentuk dan terjalin relasi keagenan diplomasi publik Korea Selatan dari mereka, baik secara sadar atau tidak, maupun secara resmi atau tidak.

Dalam kelas bahasa ini terdapat elemen listening terhadap penerimaan para murid di kelas maupun di setiap kegiatan mereka dalam program-program KSIC Indonesia yang sengaja ditujukan bagi mereka. Bersamaan dengan itu pula elemen diplomasi budaya bekerja dan disusul dengan penyiarannya kemudian di akun-akun media sosial yang dipunyai KSIC Indonesia.

\section{Kelas Khusus}

KSIC kelas khusus merupakan kelas bahasa Korea bagi para karyawan atau pekerja sebagai hasil dari kerja sama KSIC Indonesia dengan beberapa perusahaan di Indonesia. Berbeda dengan kelas regular yang dilaksanakan di gedung KSIC, kelas khusus dilaksanakan di perusahaan yang bekerja sama dengan KSIC dengan mendatangkan staf pengajar. Hal ini dilakukan agar para karyawan yang tidak memiliki waktu untuk mengikuti kelas bahasa regular dapat mendapatkan pengajaran di perusahaannya masing-masing. 
Sudah terlaksana tiga kelas khusus melalui kerja sama dengan tiga perusahaan yaitu PT. Mitra Integrasi Informatika, PT POSCO IJPC dan PT POSCO Internasional.

Dalam kelas bahasa ini terdapat elemen listening dan diplomasi budaya di dalamnya. Para staf KSIC Indonesia berupaya mendapatkan feedback yang dapat membantu membuat kelas khusus selanjutnya menjadi lebih baik lagi. Seperti halnya kelas bahasa Korea, elemen diplomasi budaya bekerja pada saat pembelajaran bahasa dilaksanakan di dalam kelas baik secara eksplisit maupun implisit.

\section{Pemberian Beasiswa}

KSIC Indonesia sampai saat ini tidak menyelenggarakan program pemberian beasiswa yang mengatasnamakan KSIC Indonesia. Namun sebagai satu bagian dengan KSIF, KSIC Indonesia memberikan kesempatan kepada seluruh murid KSIC untuk dapat mengambil bagian dari beasiswa yang diberikan oleh KSIF. KSIF memberikan beasiswa bagi murid-murid KSI termasuk yang ada di Indonesia yang ingin melanjutkan studi di Korea Selatan. Dalam pelaksanaan program beasiswa ini, KSIC Indonesia menerapkan elemen listening. Elemen listening digunakan untuk dapat mendengar masalah-masalah atau tantangan yang dihadapi oleh murid-murid KSIC dalam menjalani atau mengikuti prosedur yang ditentukan KSIF. Dengan langkah ini, KSIC Indonesia dapat membantu para muridnya tepat pada sasaran. Selain itu, elemen listening juga digunakan untuk mengetahui alasan mengapa beberapa murid belum cukup tertarik dengan program beasiswa. Hasil dari elemen ini dapat dapat menjadi masukan bagi KSIF untuk menciptakan program yang lebih baik dan lebih menarik ke depannya.

\section{Pelatihan dan Pertukaran Staf KSIC Indonesia dan Korea}

Program pelatihan bagi staf KSIC Indonesia yang mengandung elemen diplomasi pertukaran dan budaya merupakan usaha membangun relasi dengan publik Indonesia yang bermanfaat. Di satu sisi, para staf KSIC Indonesia yang terpilih dikirim untuk mengunjungi Korea Selatan guna mendapatkan pelatihan dari kantor pusat, yaitu KSIF. Kegiatan ini dilakukan untuk menjaga kualitas para staf dan menjaga keseragaman sistem untuk diterapkan di KSIC Indonesia. Selama kegiatan, para staf juga mengalami banyak pengalaman baru dan mempelajari berbagai hal baru, termasuk budaya Korea, untuk dapat dibagikan di Indonesia.

Di sisi lain, staf pengajar atau tim ahli dari Republik Korea juga berkunjung ke KSIC Indonesia untuk memberikan pelatihan kepada para pengajar di Indonesia. Selama kunjungannya, mereka menikmati dan mempelajari budaya yang ada di Indonesia melalui para staf KSIC Indonesia. Program pertukaran yang dilakukan KSIC sampai dengan saat ini baru sebatas pertukaran para pengajar dan staf selama kurang lebih satu-dua minggu.

\section{KSIC Keliling Indonesia}

Dalam usaha membangun relasi dengan publik Indonesia yang signifikan dan berpotensi berkelanjutan bagi pelaksanaan diplomasi publik Korea adalah dengan mendekati beberapa universitas dan komunitas-komunitas akademik di dalamnya yang ada di Indonesia. Sebagai satu-satunya pusat di Indonesia, KSIC Indonesia memiliki tanggungjawab yang besar untuk mempromosikan budaya negara Korea Selatan tidak hanya di ibu kota Jakarta, tetapi juga di seluruh Indonesia. Melalui media sosial KSIC Indonesia memberikan informasi yang mengundang sekolah/universitas/komunitas di Indonesia yang tertarik dalam mempelajari sejarah, bahasa, budaya dan kebiasaankebiasaan yang ada di Korea Selatan untuk mendaftarkan diri melalui e-mail.

Dengan mengumpulkan beberapa universitas/komunitas di sebuah kota di Indonesia, KSIC Indonesia akan hadir dan memberikan penjelasan yang mendalam 
mengenai budaya-budaya Korea Selatan untuk kemudian relasi-relasi dibangun untuk keajegan keberlanjutannya. Kegiatan yang tidak dipungut biaya ini telah dilaksanakan di Universitas Indonesia (Jakarta), Universitas Pendidikan Indonesia (Bandung), Universitas Komputer Indonesia (UNIKOM) dan Universitas Padjajaran (Bandung).

Selain terdapat elemen listening, melalui kegiatan promosi budaya Korea Selatan di kalangan ini diharapkan memiliki penerimaan dan prospektif yang berkualitas dan positif berjangka panjang bagi Korea Selatan.

\section{Penerimaan Publik Sasaran}

Seperti yang dikatakan oleh Leonard, bahwa pada dasarnya tujuan diplomasi publik adalah untuk memengaruhi masyarakat negara lain untuk memandang negaranya sesuai yang diinginkan, dan penerimaan publik target terdiri dari beberapa unsur hierarkis. Seberapa jauh penerimaan publik Indonesia sebagai sasaran diplomasi publik Korea Selatan oleh KSIC Indonesia di Indonesia dapat dilihat dari keberadaan unsur familiarity, appreciation, engaging people, dan influencing.
Unsur familiarity dapat dilihat dari data yang diperoleh dari PR KSIC mengenai peningkatan jumlah peserta atau murid yang mendaftarkan diri menjadi murid KSIC. Dalam kurun waktu 2 tahun sejak berdirinya KSIC Indonesia terlihat peningkatan dari 75 orang yang terdaftar sebagai murid KSIC sampai kini sekitar 2000 orang. Peningkatan ini menandakan ketidakasingan (khususnya budaya) Korea Selatan bagi publik Indonesia untuk semakin dikenali, diketahui, dipelajari dan didatangi.

Unsur appreciation dapat dilihat dari antusiasme para peserta atau murid KSIC Indonesia dalam mengikuti ragam program acara yang diadakan oleh KSIC Indonesia. Data ini dapat dilihat dari komentar dan apresiasi positif peserta dari Indonesia terhadap KSIC yang terdapat dalam akun IG KSIC Indonesia.

Unsur engaging people dapat ditemui dari data peserta yang mengikuti program pelatihan, beasiswa dan program-program baru sejenis.

Dalam setiap program, KSIC selalu membuka pendaftaran melalui media sosialnya dan setiap program memiliki kuota tertentu sesuai dengan kapasitas lokasi yang tersedia.

Gambar 2. Info kegiatan KSIC dan beberapa komentar dalam IG KSIC

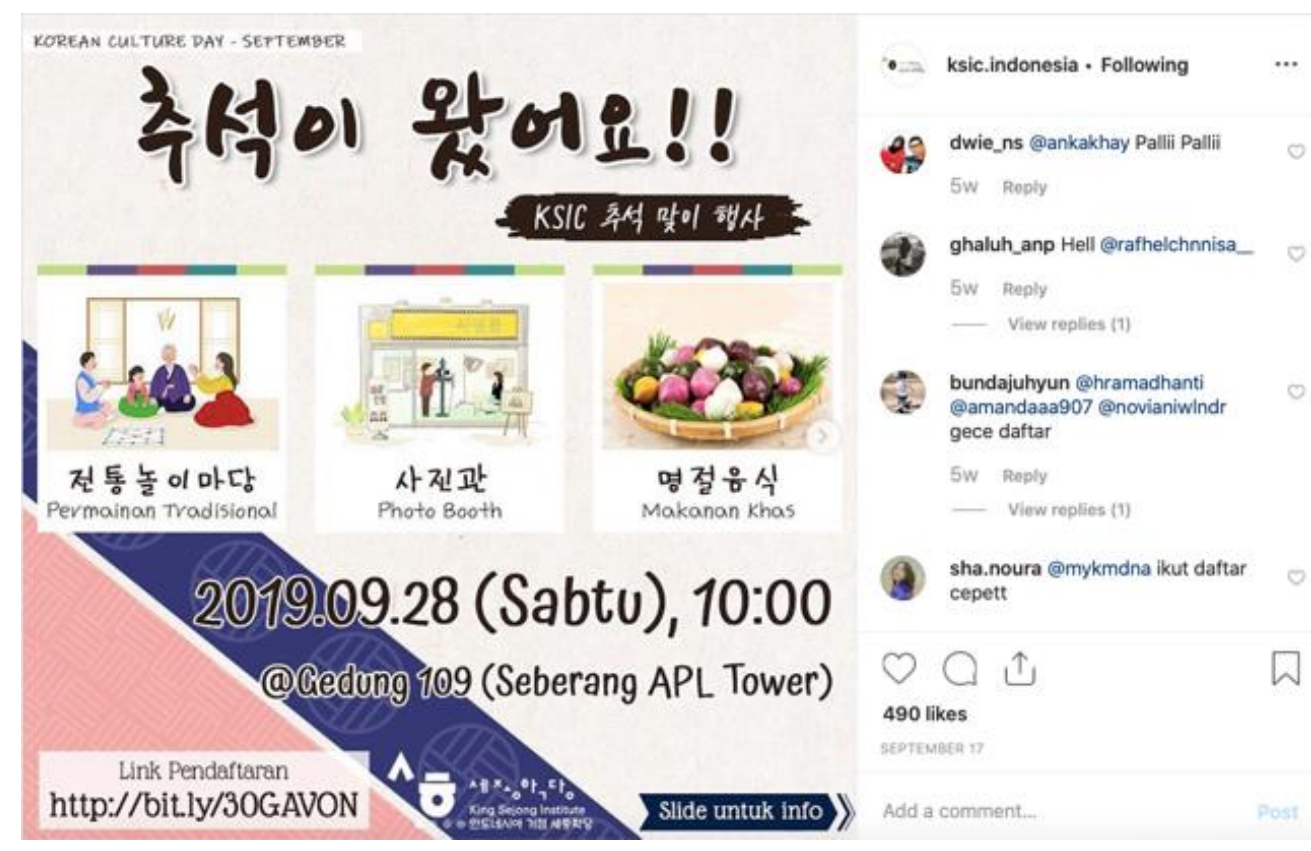


Gambar 3. Seminar yang diadakan KSIC (IG)

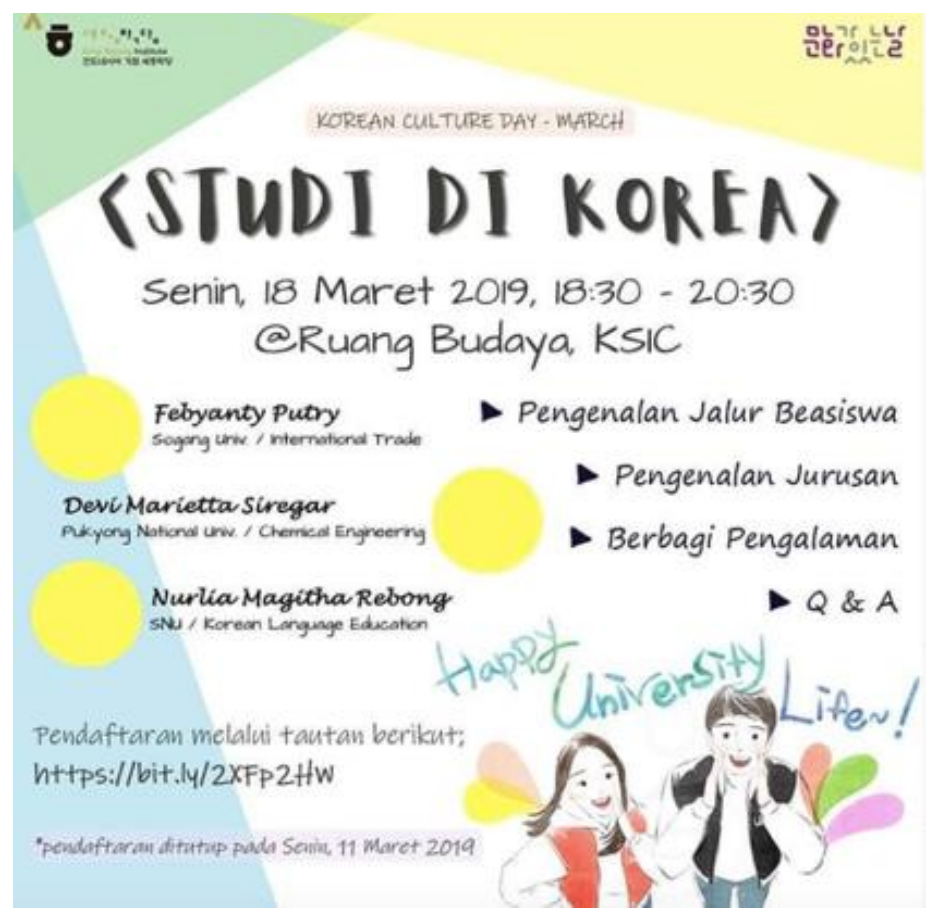

Berdasarkan data KSIC, antusisme pendaftar selalu jauh melebihi kuota yang dimiliki. Kesiapan dan keseriusan mereka untuk memenuhi syarat sebagai penerima beasiswa atau pelatihan-pelatihan di Korea Selatan untuk lebih jauh lagi mempelajari dan mengalami sendiri kehidupan di sana.

Unsur influencing dapat dilihat dari para alumnus universitas di Korea yang merupakan warga Indonesia. Mereka secara tidak langsung telah menjadi 'agen' diplomasi publik Korea dalam berbagi pengalaman positif yang menyenangkan selama di Korea Selatan untuk diikuti dan ditiru oleh publik Indonesia lainnya, khususnya para peserta seminar yang diadakan KSIC di mana ia sebagai pembicaranya.

\section{Kesimpulan}

Berdasarkan penelitian yang dilakukan mengenai diplomasi publik yang dilakukan Republik Korea melalui King Sejong Institute Center Indonesia (KSIC) dapat disimpulkan sebagai berikut. KSIC Indonesia terindentifikasi telah menerapkan beberap elemen-elemen diplomasi publik dalam kegiatan di setiap dimensi yang ada. Walaupun demikian tidak semua elemen dapat dicakup dalam setiap dimensi pelaksanaannya. Melalui diplomasi publik yang dilaksanakan ini, KSIC Indonesia dalam waktu singkat telah dapat menarik perhatian masyarakat Indonesia terutama masyarakat Jakarta di mana tempat KSIC Indonesia berada. Hasil identifikasi terhadap hierarki penerimaan publik Indonesia yang merupakan hasil dari diplomasi publik KSIC Indonesia menandai bahwa KSIC Indonesia telah melaksanakan tugasnya.

\section{Daftar Pustaka}

Cho, Y. h. (2011). Desperately Seeking East Asia Amidst The Popularity of South Korean Pop Culture in Asia. Cultural Studies.

Cull, J. N. (2009). Public Diplomacy: Lessons from the past. Los Angeles: Figueroa Press. 
Dinnie, K. (2009). Repositioning the Korea Brand to a Global Audience: Challenges, Pitfalls and Current Startegy . Korea Economics Institute Academic Paper Series, 15.

Jang, G., \& Paik, W. K. (2012). Korean Wave as Tool for Korea's New Cultural Diplomacy. Advance in Apllied Sociology.

Jones, P. (2015). Track Two Diplomacy in Theory and Practice. California: Stanford University Press.

KOCIS. (2019, March 26). Ministry Culture, Sport and Tourism. Diakses dari Korean Cultural Center: http://www.kocis.go.kr/eng/openInf ormation.do

KSIF. (2018). King Sejong Institute foundation. Diakses dari KSIs Worlwide: https://www.ksif.or.kr/ste/ksf/hkd/1 ochkd.do?menuNo=31101100.

Lee, S. J. (2012). South Korea as New Middle Power Seeking Complex Diplomacy. EAI Asia Security Initiative.

Leonard, Mark. (2002). Public Diplomacy. London: The Foreign Policy Centre.

Kim, T., Kwon, H.-J., Lee, J., \& Yi, I. (2011). "Mixed Governance" and Welfare in South Korea. Journal of Democracy.

Kwon, S.-H., \& Kim, J. (2013). Fron Censorship to Active Support: The Korean State and Korea's Cultural Industries. The Economic and Labour Relations Review.

Ministry of Foreign Affairs Republic of Korea. (2007, January 1). Ministry of Foreign Affairs Republic of Korea. diakses melalui Diplomatic White Paper: mofa.go.kr

Muchtar, J. (2018, May 8). Jakarta Globe. Hallyu: Surfin' the Korean Wave in Indonesia. Diakses melalui https://jakartaglobe.id/culture/ridin g-the-wave-of-south-korean-popculture-in-indonesia

Nye, Joseph. S. (2004). Soft Power: The Means to Success in World Politics. New York: Public Affairs.

Nye, Joseph. S. (2008). Public Diplomacy and Soft Power (Vol. 616). New York: Sage Publications, Inc.

Pinem, W. (2012, 8 9). Seni Berpikir. diakses melalui Korean Wave dan Peningkatan Perekonomian Republik Korea: seniberpikir.com

Tuch, H. N. (1990). Communicating with the world: U.S public diplomacy overseas. New York: St. Martin's Press.

Visit Korea. (2011, November 5). Imagine Your Korea. Diakses April 8, 2018, dari website Visit Korea: english.visitkorea.or.kr

Yang, J. (2012). The Korean Wave (Hallyu) in East Asia: A Comparison of Chinese, Japanese and Taiwanese Audiences Who Watch Korean TV Dramas. Development And Society. 